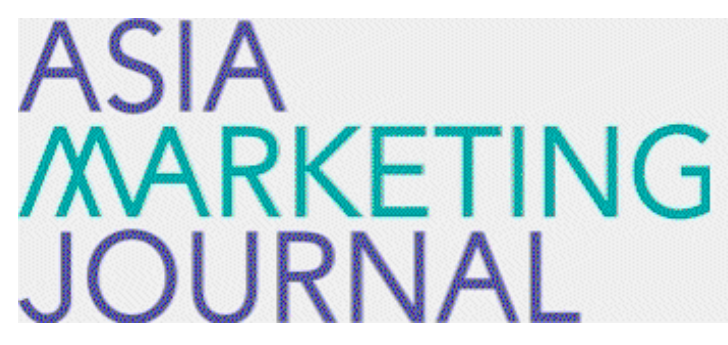

ASIA MARKETING JOURNAL

Volume 15 | Issue 4

Article 3

$1-30-2014$

\title{
The Effect of Regulatory Focus on the Link Between Purchase Behavior and Redemption Behavior
}

Ji Yoon Kim

Follow this and additional works at: https://amj.kma.re.kr/journal

Part of the Marketing Commons

\section{Recommended Citation}

Kim, Ji Yoon (2014) "The Effect of Regulatory Focus on the Link Between Purchase Behavior and Redemption Behavior," Asia Marketing Journal: Vol. 15 : Iss. 4 , Article 3.

Available at: https://doi.org/10.53728/2765-6500.1566

This Article is brought to you for free and open access by Asia Marketing Journal. It has been accepted for inclusion in Asia Marketing Journal by an authorized editor of Asia Marketing Journal. 


\title{
The Effect of Regulatory Focus on the Link Between Purchase Behavior and Redemption Behavior
}

\author{
Ji Yoon Kim*
}

Previous research on loyalty program has verified the factors that influence redemption behavior and the understanding of the mechanism of redemption behavior with academic and practical implications. However, these research has not proven boundary conditions in which the phenomena can be strengthened or weakened - that is, the moderating effect remains unclear. The inclusion of moderating variables can provide a more extensive understanding of the mechanism of this behavior from academic and managerial perspectives alike. Therefore, this current research proposes regulatory focus as a moderating variable, which has received scarce attention in the study of loyalty program behavior, especially individual characteristic variables that, in turn, affect the consumers' purchasing behavior in various ways. Previous research on consumer decision making investigates the differential role of regulatory focus as a series of stages. Regulatory focus theory posits that people depend on the two types of regulatory focus when pursuing goals: promotion focus vs. prevention focus. The former induces tendencies to recognize a goal as a hope and ideal, as something that satisfies the need for accomplishment, and to be sensitive to the presence of a positive outcome of the match and to match the pursuit of goals. On the other hand, the latter tends to regard a goal as the responsibility or obligation to achieve the goal, has a tendency to avoid failure to meet a target, and is sensitive to the presence of the negative consequences that do not reach the target.

The following propositions are suggested: 1) The effect of higher accumulation effort level on delaying point redemption speed will be relatively more pronounced for customers with prevention focus. 2) The effect of higher accumulation effort level on large redemption unit size will be relatively more pronounced for customers with prevention focus. 3) The effect of higher accumulation effort level on hedonic redemption ratio will be relatively more pronounced for customers with promotion focus.

Therefore, this research provides a moderating variable that has the potential to be used as a reference for market segmentation and affects the relationship between point accumulation effort and three sides of point redemption behavior. On this basis, the direction for the future research on this issue is recommended. Future research could verify these propositions conducting a survey of customers' propensity of regulatory focus in conjunction with the history of the loyalty program of data. This would provide a more realistic effect on the usage behavior of loyalty program consumers by providing useful implications for both marketing practitioners and researchers.

Key words: redemption speed, average redemption unit size, hedonic redemption ratio, regulatory focus, exertion of effort

\footnotetext{
* Post-Doctoral Research Fellow, Pusan National University and Research Fellow, IBRE at Korea University (jiyoonk77@naver.com)
} 


\section{Introduction}

Customer loyalty programs have received considerable attention in both academia and managerial as they grow in perceived and actual importance for a firm not only to acquire new customers but also to retain existing customers. In general, a customer loyalty program focuses on the firm's existing customer base to build a long-lasting relationship by creating added value for the customers (Dowling and Uncles 1997). The loyalty program members "redeem" their points collected and obtain various rewards, such as free flights, cashback point, or gifts. Kumar and Shah (2004, p. 328) note, "The rewards associated with loyalty programs provide a means to establish reciprocity between the customer and the company."

Point redemption behavior is an important behavior in loyalty programs. Point redemption is defined as a process to gain compensating reward using the points obtained as a result of purchasing goods and services of a particular company. The reason for companies to provide these points is largely for customer acquisition of compensation reward through point redemption, and it is based on the assumption that consumers will purchase more frequently in large quantities of goods and services from the company providing the rewards than others. The rationale is that rewards may generate an obligatory feeling from the customer that manifests as more future business, which, in turn, may lead to more rewards offered from the company, and so on. That is, the reason consumers actively use loyalty programs is generally to redeem points. In addition to this, the effect of point redemption on the loyalty of consumers is also generated from the redemption process itself as well as the process of consumers exerting effort to redeem points. In addition, consumers receive both psychological and economic advantages from redeeming earned points. This free reward operates as a positive enhancement of consumers' future purchase behavior and conditions them to continue doing business with the focal firm (Sheth and Parvatiyar 1995). Eventually, these interaction processes deepen their long-term relationship with the firm (Bitner 1995: Gwinner, Gremler, and Bitner 1998).

However, in order to use the points, they must be accumulated in advance, which inevitably requires the exertion of efforts from the consumers. While most previous research determines level of effort by calculating purchase frequency, Kim et al. (2012) defined the level of effort by the degree of consumer inconvenience in accumulating points by using a paper coupon accumulation. They empirically investigated the effect of effort level on redemption behavior. In particular, point redemption speed, average redemption unit size, and hedonic redemption ratio depending on the type of points accumulation were investigated using real-world transaction data. 
Kim et al.(2012)'s attempt is noteworthy, in that it verifies the factors that influence redemption behavior and the understanding of the mechanism of redemption behavior, and it contributes to the academic and practical implications. However, their research has not proven boundary conditions in which the phenomena can be strengthened or weakenedthat is, the moderating effect remains unclear. The inclusion of moderating variables can provide a more extensive understanding of the mechanism of this behavior from academic and managerial perspectives.

In practice, the moderating variable is the individual characteristic variables, which, in turn, affects the consumers' purchasing behavior in various ways; hence, moderating variables have the potential to be used as reference variables for market segmentation. Therefore, in this research, as Kim et al. (2012) validated, I will provide a moderating variable that will affect the relationship between point accumulation effort and three sides of point redemption behavior as well as aim to suggest the direction for future research.

\section{Review of the effect of point accumulation effort level on redemption behavior}

To determine the effect of a moderating var- iable on other variables, it is necessary to establish an explicit understanding of the mechanism of the main effect of the variable (main effect). It can be said that when there is a variable that is associated with a condition that weakens or enhances the mechanism of the main effects, such a variable has potential as a moderating variable. Therefore, to view the moderating effect of the effort level, a brief discussion is needed concerning the mechanism of the relationship between the accrual effort variable and those associated with redemption behavior.

First, according to Kim et al. (2012), the effect of level of point accumulation effort on redemption speed is caused by the phenomenon that the discount rate of the latter is higher than that of the former over time (Soman 2004, 2005). That is, when the transaction that secures monetary gains with an exerted effort is in the future, the discount rate of effort is diminishingly greater than that of the monetary reward as the time of reward approaches. As a result, overall transaction utility will be increased with the time delay of a transaction.

When the transaction is in the future, the utility of monetary gains from a transaction is discounted; however, the degree of discounting of effort level is greater than that of monetary gains; therefore, net utility of transactions is increasing (Soman 2004). Kim et al. (2012), based on this result, argued that the higher the effort level of consumers, the more that the 
distant transaction (point redemption) looks more attractive, and, thus, customers will delay their points redemption.

Second, with respect to the effects of effort level on average redemption unit size, Kim et al. (2012) suggest an underlying mechanism in their study as a shift of reference point with the increase in the level of effort. In other words, according to Kivetz (2003), consumers who exerted effort would expect a compensation for such efforts, and these expectations will bring the shift of reference point, which is the basis of the evaluation of the utility. In other words, for consumers who exert effort, in order to perceive a reward as a gain, a higher level of reward (relative to effort) is required. Therefore, Kim et al. (2012) expect that consumers who exert a great deal of effort would expect a higher level of reward so that the propensity to redeem a large amount of points will be increased. In other words, the above studies argue that consumers with a high level of accumulation effort spend a large amount of points per transaction.

Third, regarding the effect of effort level on the hedonic redemption site, Kim (2012) propose the following underlying arguments. First, the purchase or consumption of hedonic products is to allow consumers to feel guilty (Lascu 1991; Prelec and Herrnstein 1991; Strahilevitz and Myers 1998; Thaler 1980). Second, the guilty feeling of hedonic consumptions tends to be alleviated through the justification of the desired behavior such as donation, exertion of effort, and hard work.

Therefore, the above research asserts that as the expected effort will alleviate the guilty feeling of hedonic consumption, Kim(2012) also empirically investigate Kivetz and Simonson (2002)'s experimental examination of consumers indicating that high effort customers have a tendency to choose a luxury reward rather than a utilitarian reward by incorporating realworld purchase loyalty program data.

\section{Regulatory focus as a moderating variable on the link between point accumulation effort and point redemption behavior}

It is possible to list the following variables as consumer characteristic variables that could be moderating variables with the impact of accumulation effort level on redemption behavior, as Kim (2012) demonstrated.

- Moderating effect on the redemption speed: a consumer characteristic variable that indicates the degree to which the consumer perceives the exertion of effort as a loss

- Moderating effect on the redemption unit size: a consumer characteristic variable that indicates the degree to which the consumer 
perceives the exertion of effort as a loss

- Moderating effect on the hedonic redemption ratio: a consumer characteristic variable that indicates the degree to which consumers prefer hedonic (rather than utilitarian) redemption

Therefore, this research proposes a dispositional regulatory focus as a customer characteristic variable that corresponds to these relationships in general. Regulatory focus theory insists that people depend on the two types of regulatory focus when pursuing goals. Individual motivational tendency could be classified into promotion focus and prevention focus. Promotionfocused individuals have a tendency to recognize their goal as a hope and ideal, as something that satisfies the need for accomplishment. They are sensitive to the presence of a positive outcome of the match and have the tendency to match the pursuit of goals. On the other hand, individuals with a prevention focus tend to regard their goal as the responsibility or obligation to achieve goals, have a tendency to avoid the failure to meet a target, and are sensitive to the presence of the negative consequences that do not reach the target. As a result, regulatory focus theory argues that prevention-focused individuals have a relatively strong tendency to put the focus on the minimization of loss in decision-making and information analysis, while individuals with a promotion focus have a relatively strong pro- pensity to focus on the maximization of gain.

Pham and Higgins (2004) discuss how regulatory focus theory can be applied to explain the consumer decision-making process. That is, the above research investigates the differential role of regulatory focus in consumer decision making as a series of progressing stages through (1) problem recognition, (2) search of information, (3) consideration set formation, (4) evaluation of alternatives, (5) choice/purchase, and (6) post-choice/post-purchase processes (Hoyer and MacInnis 2003).

Therefore, it can be inferred that regulatory focus theory could affect consumers' decisionmaking process in point redemption behavior.

Based on this literature, this research proposes the following specific propositions that the accumulation effort on point redemption behavior will be moderated by consumers' dispositional regulatory focus.

\subsection{Moderating effect of accumulation effort level on the redemption speed}

As Soman (2004, 2005) and Kim et al. (2012) point out, the delayed effect on point redemption with high exerted effort is due to the different discount rates between the monetary gains with transaction and time. However, point redemption, in other words, is redefined as the exhaustion of exerted effort, which is regarded as a loss. The acquisition of rewards by $\mathrm{re}^{-}$ deeming points is an action in which the con- 
sumer acquires a reward as a gain instead of a forfeit of possessed points. Therefore, in the case of a consumer who is more sensitive to the loss that is a forfeit in the form of possessed points, the perceived utility of points and reward equivalent to the amount is relatively low at some future point. In addition, in the case of these consumers, the time difference between current behavior and the point redemption action that is required for the point redemption behavior to be perceived attractive would be relatively large. That is, in the case of customers who are more sensitive to the loss, a longer time is required for the effort to be discounted to a sufficient level. Therefore, in the case of customers with a prevention focus, it is possible to predict that the tendency to postpone redeeming points so as to reduce accumulated effort is relatively strong. From this point of view, proposition 1 is proposed.

Proposition 1: The effect of higher accumulation effort level on delaying point redemption speed will be relatively more pronounced for customers with a prevention focus.

\subsection{Moderating effect of accumulation effort level on the redemption unit size}

Kim et al. (2002) point out that, according to Kahneman and Tversky (1979), the reference point in utility evaluation corresponds to the status quo (current position) and "there are situations in which gains and losses are coded relative to an expectation or aspiration level that differs from the status quo" (Kahneman and Tversky 1979, p. 286). In addition, increasing the customers' exertion of effort leads to a shift in the reference point, which will result in the expectation of a larger amount of rewards. Rewards that meet or exceed the expectation raised by the concomitant effort level will be perceived as gains, whereas rewards that fail to meet the expectation level will be coded as losses (Kivetz 2003; Kim et al. 2012). In this case, the customer group that is more concerned with perceiving point redemption behaviors as losses due to the failure to meet the expectation level is the group of people with a prevention focus who are highly sensitive to loss. In order to avoid the risk of a loss for those prevention-focused groups of people, the level of a compensation reward must be increased sufficiently. In other words, as the level of compensation benefits of a reward is increased, the possibility of the level of utility of the reward failing to meet the expectation will be decreased. In situations where the loyalty program reward standard is already determined based on the program policy, companies can increase the benefits of the gain of compensation for consumers by making them acquire rewards in large amounts (gain). Rather than using a few points, they are required to use points in large quantities at a time. In other 
words, the tendency to redeem a large unit size in a transaction, so as not to perceive it as a loss as a whole with the high exertion of effort, will be relatively strong in the case of consumers with a prevention focus who are more sensitive to such losses.

Proposition 2: The effect of higher accumulation effort level on large redemption unit size will be relatively more pronounced for customers with a prevention focus.

\subsection{Moderating effect of accumulation effort level on the hedonic redemption ratio}

According to Kim (2012), the effect of effort level on the preference for hedonic redemptions is based on the notion that higher effort serves as a guilt-reducing justification of exertion of effort for choosing hedonic rewards over necessities (Kivetz 1999; Kivetz and Simonson 2002). This account implies that consumers who are more predisposed to feeling guilt when consuming hedonic goods should be particularly sensitive to the level of effort when considering loyalty point rewards. If so, in the case of consumers' relatively high preference for hedonic consumption regardless of the level of effort, these effects of the acquisition effort level of point appear relatively weak with the effort level. Since, without justification through the efforts of the points, consumers of these types are relatively open to the hedonic consumption already.

According to Chernev (2004), consumers with a promotion focus have a tendency to put more importance on hedonic value, while those with a prevention focus place more importance on utilitarian value. In other words, in the case of consumers with a promotion focus, it is $\mathrm{ex}^{-}$ pected that the extent to which they enjoy hedonic consumption is naturally already higher than that of consumers with a prevention focus. Therefore, in the case of consumers with a promotion focus, the impact of effort level on hedonic redemption rate in a business site can be expected to be relatively weaker than those with a prevention focus. Therefore, I propose a following proposition 3 :

Proposition 3: The effect of higher accumulation effort level on the hedonic redemption ratio will be relatively more pronounced for customers with a promotion focus.

\section{Concluding Remarks}

This research, starting from Kim (2012)'s empirical investigation, theoretically investigates the possibility of the moderating effect of consumers' dispositional regulatory focus on the link between point accumulation effort and redemption behaviors. In other words, this research sug- 
gests the possibility of a moderating effect of regulatory focus on the link between points accumulation effort and subsequent behaviors such as point redemption speed, average unit size per transaction, and hedonic-site redemption rate. From the study of Kim (2012) and other previous research, all of these effects could be moderated by the consumer's regulatory focus. Although this study does not present experimental or empirical evidence on the propositions, it contributes in that it theoretically and logically investigates the possibility of the abovementioned moderating effect. It is $\mathrm{ex}^{-}$ pected that future research could expand upon the starting point of this research using experimental data or real-world purchase data.

Despite this limitation, this research is meaningful in terms of its basis for future research.

This research has been noted by Kim et al. (2012)'s variables; that is, the points accumulation effort levels measured by means of a point accumulation method, point redemption speed, average unit points per redemption, and hedonic redemption ratio can be extracted from the loyalty program members' actual panel data. In addition, these variables are those that are very interesting in practice. That is, these variables are important, in that they not only receive practicable insight easily, but also offer strong external validity of the analysis result (Winner 1999) as compared with the case of experimental data. Verifying these propositions by conducting a survey of customers' propen- sity of regulatory focus in conjunction with the history of loyalty program data would provide a more realistic view of the usage behavior of loyalty program consumers in general.

〈Received December 13. 2013〉

〈Revised January 13. 2014〉

〈Accepted January 15. 2014〉

\section{References}

Bitner, Mary Jo (1995), “Building Service Relationships: It's All About Promises," Journal of the Academy of Marketing Science, 23 (Fall), 246-251.

Chernev, A. (2004), "Goal-attribute compatibility in consumer choice," Journal of Consumer Psychology, 14 (1), 141-50.

Dowling, Grahame R. and Mark Uncles (1997), "Do Customer Loyalty Program Really Work?," Sloan Management Review, Summer, 71-82.

Gwinner, Kevin P., Dwayne D. Gremler, and Mary Jo Bitner (1998), "Relational Benefits in Services Industries: The Customer's Perspective," Journal of the Academy of Marketing Science,26 (Spring), 101-114.

Higgins, E. T. (1997), “Beyond pleasure and pain," American psychologist, 52 (12), 1280300.

Higgins, E. T. (2000), “Making a good decision: value from fit," American psychologist, 55 
(11), 1217-30.

Hoyer, W. D., and MacInnis, D. J. (2003). Consumer Behavior (3rd ed.). Boston, MA: Houghton Mifflin.

Kahneman, Daniel and Amos Tversky (1979), "Prospect Theory: An Analysis of Decision Under Risk," Econometrica, 47 (March), 263-291.

Kim, J. Y. (2012), “A Study on the consumers' effort level, redemption behavior, and loyalty in Loyalty Program” Doctoral Dissertation, Business School, Korea University.

Kim, J. Y., J. Lee, S. Y. Kim, and B. H. Lee (2012), "The Effects of Point Accumulation Effort Level on Redemption Behavior in Loyalty Program," Journal of Korean Marketing Association, 27 (1), 85-106.

Kivetz, Ran (1999), “Advances in Research on Mental Accounting and Reason-Based Choice," Marketing Letters, 10 (3), 249-66. Kivetz, Ran(2003), "The Effects of Effort and Intrinsic Motivation on Risky Choice," Marketing Science, 22(4), 477-502.

Kivetz, Ran and Itamar Simonson (2002), "Earning the Right to Indulge: Effort as a Determinant of Customer Preference toward Frequency Program Rewards," Journal of Marketing Research, 34(May), 155-170.

Kumar, V. and D. Shah(2004), "Building and Sustaining Profitable Customer loyalty for the 21st century," Journal of Retailing, 80, 317-330.

Lascu, Dana N. (1991), “Consumer Guilt: Exa- mining the Potential of a New Marketing Construct," Advances in Consumer Research, Vol. 18, Rebecca Holman and Michael Solomon, eds. Provo, UT: Association for Consumer Research, 290-293.

Pham, M. T. and Avnet, T. (2004), "Ideals and oughts and the reliance on affect versus substance in persuasion," Journal of Consumer Research, 30 (4), 503-18.

Prelec, Drazen and Richard J. Herrnstein (1991), "References or Principles: Alternative Guidelines for Choice," in Strategy and Choice, Richard J. Zeckhauser, eds. Cambridge, MA: MIT Press, 319-340.

Sheth, Jagdish N. and Atul Parvatiyar (1995), "Relationship Marketing in Consumer Markets: Antecedents and Consequences," Journal of the Academy of Marketing Science, 23 (Fall), 255-271.

Soman, D. (1998), "The Illusion of Delayed Incentives: Evaluating Future Effort-Monetary Transactions," Journal of Marketing Research, 35(4), 427-237.

Soman, D. (2004), "The effect of time delay on multi-attribute choice," Journal of economic psychology, 25 (2), 153-175.

Soman, D., George Ainslie, S. Frederick, X. Li, J. Lynch, P. Moreau, A. Mitchell, D. Read, A. Sawyer, Y. Trope, K. Wertenbroch, and G. Zauberman (2005), "The Psychology of Intertemporal Discounting: Why are distant Events Valued Differently from Proximal Ones," Marketing Letters, 16 
(3/4). 347-360.

Strahilevitz, Michal A. and John G. Myers (1998), "Donations to Charity as Purchase Incentives: How Well They Work May Depend on What You Are Trying to Sell," Journal of Consumer Research, 24(March), 434-446.
Thaler, Richard H. (1980), "Toward a positive theory of consumer choice," Journal of Economic Behavior and Organization, 1, 39-60. Winer, R. S. (1999), "Experimentation in the 21st century: the importance of external validity," Journal of the Academy of Marketing Science, 27 (3), 349-358. 